\title{
Point Bar Numerical Simulation and Results Analysis in the Daqing Oilfield D Block
}

\author{
Peng Huang ${ }^{1, \mathrm{a}}$, Sharong $\mathrm{Li}^{1, \mathrm{~b}}$, Qi Wang ${ }^{1, \mathrm{c}}$ \\ ${ }^{1}$ Geoscience College,Northeast Petroleum University,Daqing,Heilongjiang 163318,China \\ ahuangpengpeng1993@126.com, ${ }^{\mathrm{b}} \mathrm{m} 13115432737 @ 163 . c o m,{ }^{\mathrm{c}}$ wangqi7391@sina.com
}

Keywords: oil saturation; point bar; numerical simulation

Abstract.point bar reservoir is the key development object in the late development of Daqing Oilfield, in this paper, the numerical simulation based on the construction of the point bar is carried out on the basis of the modeling of the point bar. Through dynamic data generating simulated well history and acquiring X-unit splitting factor, carry out history matching on this basic. The results of numerical simulations reveal that oil saturation has belt distribution characteristics on the pane is influenced by the lateral accretion interlayer on oil-water flooding, by lateral accretion interlayer updip pinchout control, the remaining oil is mainly located in the middle and upper part of the lateral accretion. In view of the above characteristics, using horizontal wells to develop the remaining oil on the top of point bar has good results, and it has been confirmed by the further results of the numerical simulation.

\section{Introduction}

With the development of oil field, in particular, into the high and extra high water-cut period, the internal structure adjustment of thick oil reservoir has become a restriction to the stable production of the old oil field. It is an important technology to achieve a true sense of the "old oil field secondary development", the point bar is the main body in thick oil layer, the residual oil distribution is directly related to the follow-up plan, so it is important to simulate the numerical simulation on the basis of scientific geological model. D block of Daqing oilfield, the structure is relatively flat, the target layer $\mathrm{X}$ deposition time unit is a delta plain deposit, and well develop meandering distributary channel,and its sedimentary characteristics are representative in Daqing oilfield, the target layer $\mathrm{x}$ deposition time unit is the key segment of the thick oil layer structure adjustment in the third oil recovery at present. In this paper, the numerical simulation based on the construction of the point bar is carried out on the basis of the modeling of the point bar,this result has laid a solid foundation for the development of the future development plan.

\section{The establishment of the geological model of the meandering river point bar}

This study is based on the fine geological anatomy,taking the facies control as the background,the technical constraints condition of the lateral accretion layer and PETREL software as a means, the point bar geological model of the study area has been established(see Figure 1). the model can fully restore the spatial structure of the thin layer in the sand body of the point bar body,section is " $\int$ " type or anti-f "type imbricated character of the top and bottom slow and the middle steep; in the plane, trajectory set point of intersection what is inflection point of the abandoned channel of meander ring two sides and the abandoned channel of meander ring what is the inward curvature gradually decreasing arc group of the external envelope surface provide a scientific geological model for numerical simulation. 


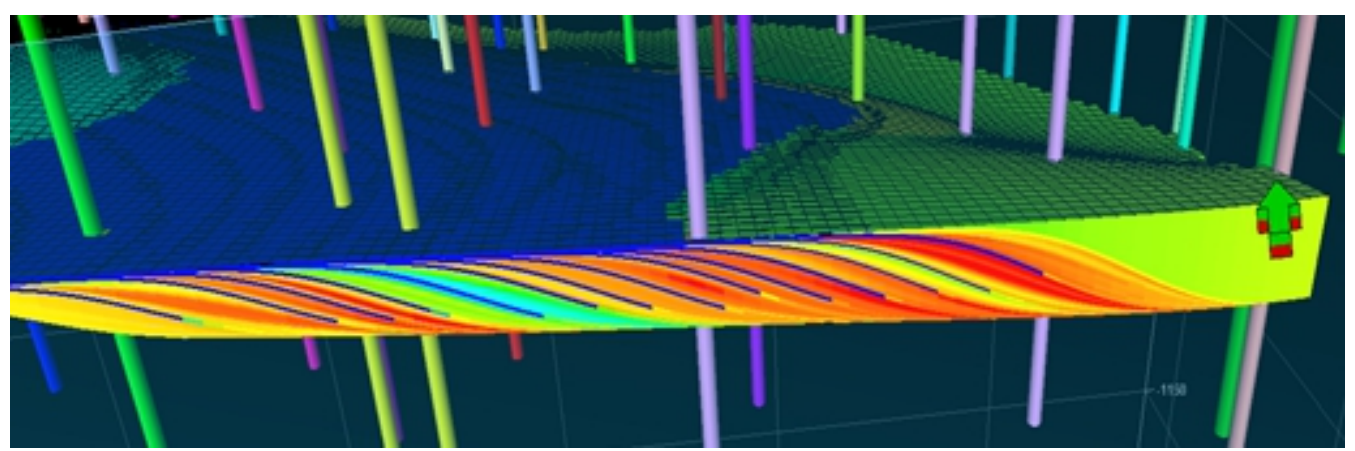

Fig. 1 The 3D geological model of the point bar

\section{Numerical simulation of point bar}

Build a simulated work area:take coarsening on fine geological model of PETREL, the plane grid step length from $5 \mathrm{~m} \times 5 \mathrm{~m}$ into $15 \mathrm{~m} \times 15 \mathrm{~m}$. Seamless link between the fine geological model and the simulation model is realized. The crude model acting as a geological model,building up simulated work area by the production history data of 9 wells and perforating data.

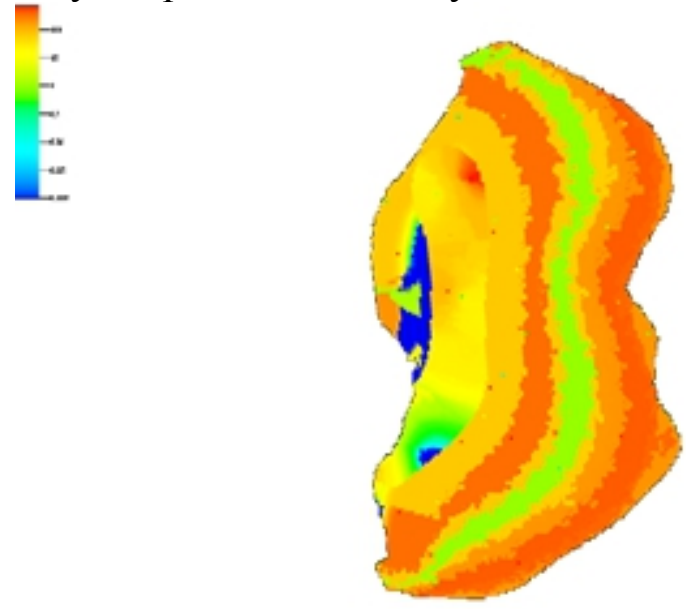

Fig. 2 The numerical simulation model of point bar

The simulation parameters selecting: 55 relative permeability curves were selected according to different permeability and porosity,and the seepage law of oil reservoir is described accurately.

Reservoir fluid property parameters:collect and collate the various fluid properties of the research block ground and formation, obtaining a variety of basic physical parameters of reservoir numerical simulation.

history matching: the oil production rate, water production rate, and the water cut of the block was matched by the simulation calculation, Fig. 3 and Fig. 4 analog curves show that the average absolute analog error of moisture content and cumulative oil is respectively $1.2 \%$ and $4.25 \%$.

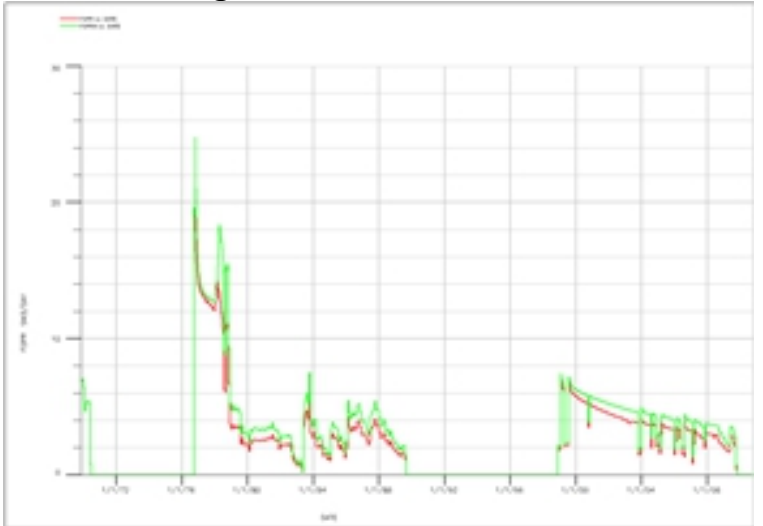

Fig. 3 Matching curve of oil production rate

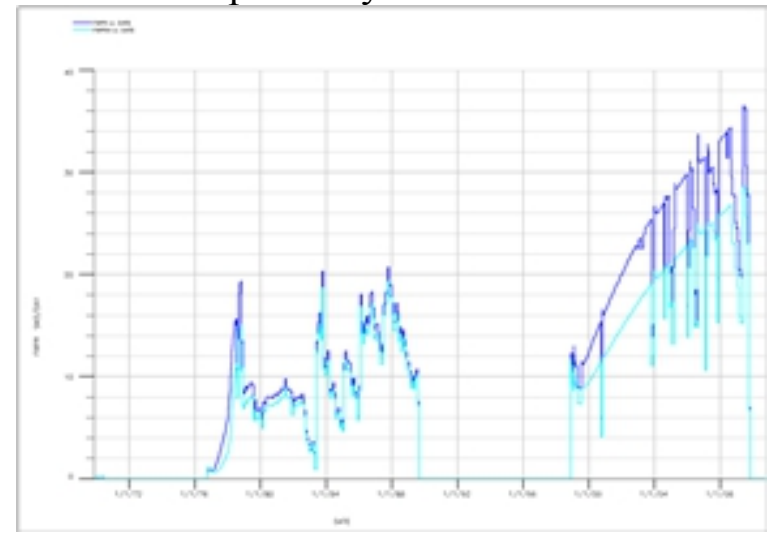

Fig. 4 Matching curve of oil production rate 


\section{The discussion of the numerical simulation results}

Through the analysis of the results of numerical simulation, Get the following three aspects:

(1) Displacement characteristics on plane is strip distribution characteristics

In Fig. 5, remaining oil gradually reduce from west to east with a strip. The plane distribution of the strip plane and the plane distribution of the lateral accretion shale are consistent. The above show that lateral accretion mudstone play a shelter effect to injected fluid; the flooding scale is much higher along lateral accretion body. So the remaining oil is less.
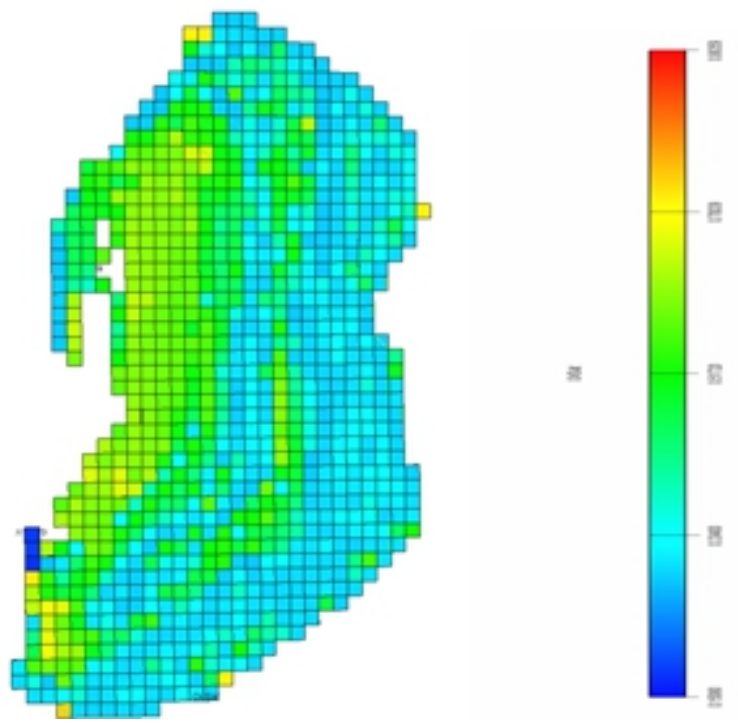

Fig. 5 Bottom oil saturation distribution map

\section{(2) wells in the point bar, lateral spread Limited}

In Figure 6, the WELL1 is a water injection well,the water flooding degree is high, and the oil saturation is low.at the same time bottom oil saturation is low, the upper part is high and oil saturation of the both sides increasing. Main reasons are that lateral accretion mudstones is updip pinchout owing to no relieving pressure; At the same time, in the case of gravity and lateral accretion shale on both sides of the limiting flow,injected water moved to downward in the same lateral accretion body,result in the lower part flooded seriously and it is difficult to spread to other lateral accretion body,while the both sides are flooding low and oil saturation high.

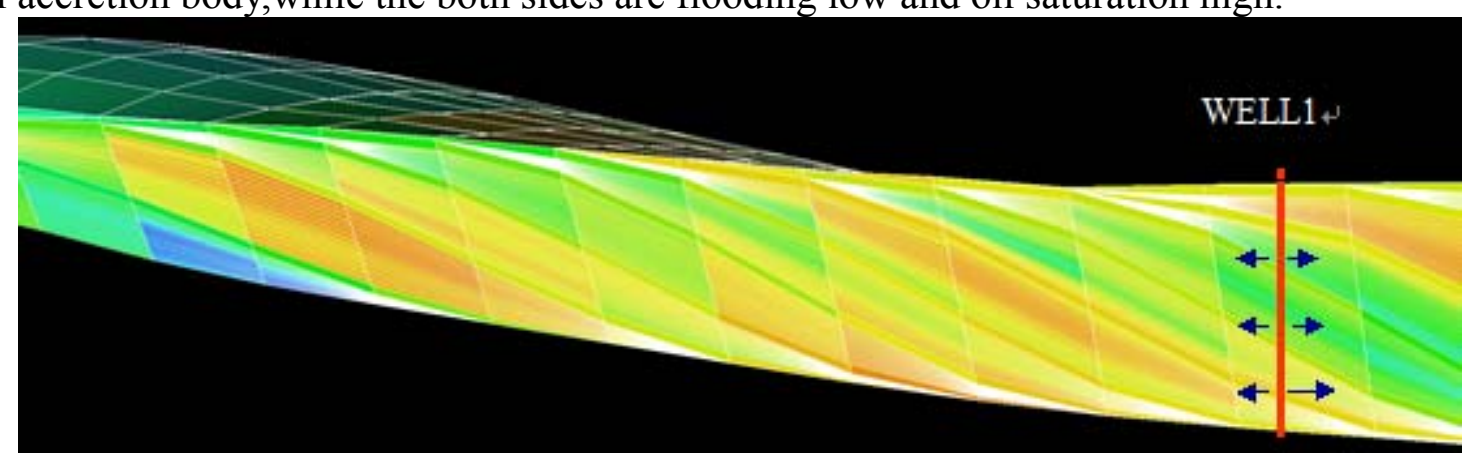

Fig. 6 The remaining oil distribution profile

\section{(3)The remaining oil is mainly distributed in the middle and upper part of the lateral accretion}

In Figure 7, the oil saturation has the characteristics of obvious upward, the cause of this result is the tip of the mudstone, injected fluid diffcultly spreading in the top of lateral accretion body resulting in much more remaining oil. Whereas the middle and bottom can be spread, so the oil saturation is low, and the lowest in the bottom. 
Fig. 7 The remaining oil distribution profile of the point bar

\section{Numerical simulation of development measures}

According to the numerical simulation results of the point bar, A horizontal well is designed to develop the remaining oil in the middle of the point bar. The designed horizongtal well liquid production and injection-production ratio is respectively $80 \mathrm{~m} 3 / \mathrm{d}$ and $1: 1$ until water content reaching 98\%. Oil output and water content is respectively $8.8 \mathrm{~m} 3 / \mathrm{d}$ and $92.31 \%$ in the initial production. Oil output and water content is respectively $3.8 \mathrm{~m} 3 / \mathrm{d}$ and $97.46 \%$ after one year. The results show that horizontal wells can be used as one of potential means.

\section{Conclusions}

Geological analysis and numerical simulation results reveal that thin interbed of point bar has strong restraining effect to flowing characteristic of fluid.Firstly,oil saturation on plane is strip distribution characteristic.Secondly, injection wells transverse spread is limited by the lateral accretion interbed control. Thirdly,the remaining oil is mainly located in the middle and upper part of the lateral accretion. Taking the horizontal wells in point bar is a good method for developing remainingoil in point bar.

\section{References}

[1] Miall A D. Architecture element analysis: A new method of facies analysis applied to fluvial deposits[J]. Earth Science Review, 1985, 22(4): 261-308.

[2] Miall A D. Reservoir heterogeneities in fluvial sandstone: Lessons from outcrop studies[J]. AAPG Bulletin, 1988, 72(6): 682-697.

[3] Miall A D. Reconstructing the architecture and sequence stratigraphy Vol. 41 No.5 of the preserved fluvial record as a tool for reservoir development: A reality check[J]. AAPG Bulletin, 2006, 90(7): 989-1002.

[4] Labourdette R, Jones R R. Characterization of fluvial architectural elements using a three-dimensional outcrop data set: Escanilla braided system, South-Central Pyrenees, Spain[J]. Geosphere, 2007, 3(6): 422-434.

[5] Best J L, Ashworth P J, Bristow C S, et al. Three-dimensional sedimentary architecture of a large, mid-channel sand braid bar, Jamuna River, Bangladesh[J]. Journal of Sedimentary Research, 2003, 73(4): 516-530.

[6] Ma Shizhong, Yang Qingyan.The depositional model,3-Darchitecture and heterogeneous model of point bar in meandering channels[J].Acta Sedimentologica Sinica, 2000, 18(2): 241-247.

[7] Ma Shizhong, Sun Yu, Fan Guangjuan, et al. The method fo studying thin interbed architecture of burial meandering channel sandbody[J]. Acta Sedimentologica Sinica, 2008, 26(4): 632-639.

[8] Yue Dali, Wu Shenghe, Tan Heqing, et al. An anatomy of paleochannel reservoir architecture of meandering river reservoir: A case study of Guantao Formation, the west 7th block of Gudong oilfield[J]. Earth Science Frontiers, 2008, 15(1): 101-109. 